\title{
Gut microbiota-derived short-chain fatty acids and kidney diseases
}

This article was published in the following Dove Press journal:

Drug Design, Development and Therapy

\section{Lingzhi Li \\ Liang Ma \\ Ping Fu}

Kidney Research Institute,

Department of Nephrology, West

China Hospital of Sichuan University,

Chengdu 61004I, China
Correspondence: Liang Ma; Ping Fu Kidney Research Institute, Department of Nephrology, West China Hospital of Sichuan University, No. 37 Guoxue Alley, Wuhou District, Chengdu 61004I, China Tel +8628 85I6 4I67; +8628 85421085 Email liang_m@scu.edu.cn; fupinghx@163.com

\begin{abstract}
Gut microbiota and its metabolites play pivotal roles in host physiology and pathology. Short-chain fatty acids (SCFAs), as a group of metabolites, exert positive regulatory effects on energy metabolism, hormone secretion, immune inflammation, hypertension, and cancer. The functions of SCFAs are related to their activation of transmembrane $G$ protein-coupled receptors and their inhibition of histone acetylation. Though controversial, growing evidence suggests that SCFAs, which regulate inflammation, oxidative stress, and fibrosis, have been involved in kidney disease through the activation of the gut-kidney axis; however, the molecular relationship among gut microbiotaderived metabolites, signaling pathways, and kidney disease remains to be elucidated. This review will provide an overview of the physiology and functions of SCFAs in kidney disease.
\end{abstract}

Keywords: gut microbiome, short-chain fatty acids, kidney diseases, gut-kidney axis

\section{Introduction}

The human intestinal tract harbors a diverse and complex microbial community, which plays a pivotal role in health. In recent years, gut microbiota-derived metabolites have been shown to influence host physiology and pathology. Changes in these metabolites exert major consequences, both harmful and beneficial, to the host's health. On one hand, metabolites - particularly, short-chain fatty acids (SCFAs) - are generally proven to promote health. ${ }^{1-3}$ On the other hand, uremic toxins, including indoles, ammonia, and trimethylamine $\mathrm{N}$-oxide, produced by the gut microbiota enhance the development and progression of chronic kidney disease (CKD). ${ }^{4-7}$ An insufficiency in gut microbiota-generated SCFAs is also associated with illnesses, including inflammatory bowel disease, obesity, type 1 and 2 diabetes mellitus, autism, major depression, colon cancer, as well as kidney diseases - the focus of the discussion. ${ }^{8-11}$ The functions of SCFAs are mainly related to their activation of transmembrane G protein-coupled receptors (GPCRs) and their inhibition of histone acetylation (HDAC). ${ }^{12}$ Due to their positive effects, therapeutic studies of SCFAs have been carried out both in clinical and in animal studies. However, the mechanisms of SCFAs in the gut-kidney axis have yet to be fully explored. This review will provide an overview of the physiology and functions of gut microbiota-derived SCFAs in kidney disease. Before we outline the known roles of SCFAs in renal diseases, we will first review what is known regarding the basic functions and systemic roles of SCFAs.

\section{Gut microbiota-derived SCFAs Definition, production, and transportation of SCFAs}

SCFAs are straight-chain saturated fatty acids composed of less than six carbon atoms, among which acetate (two carbons), propionate (three carbons), and butyrate 
(four carbons) are the most abundant in the human intestinal tract. ${ }^{13}$ These SCFAs are the end products of fermentation by the microbiota from complex polysaccharides, ${ }^{14}$ including non-digestible dietary fibers like inulin ${ }^{15}$ and endogenous substrates like epithelial-derived mucus. ${ }^{16}$ SCFAs not only exist in the gut but also could be absorbed in the bloodstream. ${ }^{17}$ There are two main mechanisms of SCFA absorption from the gut to the circulatory system: anion exchange between SCFAs and $\mathrm{HCO}_{3}$ - across the membrane and diffusive movement promoted by the $\mathrm{pH}$ gradient during the diffusion of protonated SCFAs. ${ }^{18}$ When entering the circulatory system, SCFAs influence several physiology process as ligands for G-protein couple receptors (GPR41, GPR43, GPR109A, and olfactory receptor 78 ) or as epigenetic regulators (HDAC inhibitors). ${ }^{2}$

Multiple factors affect the concentration of SCFAs in the gut, including the amount/type of fermentable carbohydrate consumption, the composition/diversity of the microbiota, and the interactions between microbes and the host. Moreover, mother-to-child transmission is involved in the gut microbiota and its metabolites; for instance, the mode of delivery (vaginal birth or caesarean section) and feeding patterns (breastfed or bottle-fed infants) play a role in the formation of intestinal microbiota and microbial products. ${ }^{19}$

\section{Receptors and epigenetic regulation related to SCFAs}

The physiological roles of SCFAs are mainly to act as ligands for GPCRs or as inhibitors of HDAC. ${ }^{2,20}$ GPR41 and GPR43, which are the most studied, are shown to be activated by SCFAs. ${ }^{21}$ GPR41 is widely distributed in adipose tissue and at low levels in the spleen, lymph nodes, bone marrow, peripheral blood mononuclear cells, and blood vessel endothelial cells, ${ }^{21}$ while GPR43 is primarily expressed in immune cells, adipocytes, islets, and gastrointestinal tract. GPR43 has a potential role in inflammation and metabolic disorders. ${ }^{22-25}$ More importantly, GPR41 and GPR43 both are expressed in the kidney and renal arteries. ${ }^{26}$ The potencies of SCFAs are different, but the rank order has remained generally consistent among different investigators (Table 1). ${ }^{21,27}$ Olfr78 is another key receptor for SCFAs, which is expressed on vascular smooth muscle cells, including subset of large renal vessels, renal afferent arteriole, and juxtaglomerular apparatus, where it participates in the regulation of renin secretion in response to SCFAs. ${ }^{26,28}$ Unlike other receptors, Olfr78 is more sensitive to acetate and propionate but not to butyrate. In addition, GPR109a is reported to express on gut epithelial cells, adipocytes, macrophages, and dendritic cells, which only respond to butyrate and not to acetate or propionate. ${ }^{29-32}$ Finally, when it comes to the physiological role as HDAC inhibitors, compared to propionate, butyrate is more potent in terms of pan-inhibitory activity. SCFAs affect the expression of genes with diverse functions by inhibiting the activity of HDAC to exhibit anti-tumor, antifibrotic, and anti-inflammatory activities. ${ }^{20,33}$ Additionally, SCFA-mediated inhibition of HDACs might be independent of GPCRs and GPR41 is involved in the process. ${ }^{34}$

\section{The functions of SCFAs}

As reported, SCFAs regulate tissue-specific health, as well as systemic health, including appetite, gastrointestinal motility, colitis, metabolic syndrome, airway disease, and even carcinogenesis. ${ }^{35-37}$ All of these influences are derived from the complex functions of SCFAs, including influencing

Table I The expression and major functions of SCFAs receptors

\begin{tabular}{|c|c|c|c|}
\hline Receptors & Ligands & Expression & Functions \\
\hline $\begin{array}{l}\text { GPR4I } \\
\text { (FFAR3) }\end{array}$ & $\mathrm{C} 3>\mathrm{C} 4>\mathrm{C} 2$ & $\begin{array}{l}\text { Colonic, small intestinal epithelium, enteroendocrine, } \\
\text { enteric neuronal cells, sympathetic ganglia, adipose } \\
\text { tissue, pancreas, renal smooth muscle cells }\end{array}$ & $\begin{array}{l}\text { Metabolism: regulation of gut hormones; immune: } \\
\text { epithelia innate immunity, increases Treg generation } \\
\text { and hematopoiesis of DCs from bone marrow; } \\
\text { sympathetic activation }\end{array}$ \\
\hline $\begin{array}{l}\text { GPR43 } \\
\text { (FFAR2) }\end{array}$ & $\mathrm{C} 2, \mathrm{C} 3$ & $\begin{array}{l}\text { Colonic, small intestinal epithelium, enteroendocrine } L \\
\text { cells, adipose tissue, leukocytes (eosinophils, basophils, } \\
\text { neutrophils, monocytes, dendritic cells), skeletal } \\
\text { muscle, heart, vascular endothelium in the myometrium }\end{array}$ & $\begin{array}{l}\text { Metabolism: adipocyte development, adipogenesis, } \\
\text { anti-lipolysis, regulation of gut hormones (secretion of } \\
\text { PYY and GLP-I); immune: innate immunity and Treg } \\
\text { differentiation; anti-inflammation; anti-tumor activity }\end{array}$ \\
\hline GPRI09a & C4, niacin & $\begin{array}{l}\text { Intestinal epithelial cells, adipocytes, dendritic cells, } \\
\text { macrophages, neutrophils, hepatocytes, epidermis in } \\
\text { squamous carcinoma }\end{array}$ & $\begin{array}{l}\text { Metabolism: anti-lipolysis, HDL metabolism; immune: } \\
\text { increases Treg generation and DC trafficking, } \\
\text { decreases Th } 17 \text { cells; anti-tumor activity }\end{array}$ \\
\hline Olfr78 & $\mathrm{C} 2, \mathrm{C} 3$ & $\begin{array}{l}\text { Large renal vessels, renal afferent arterioles, extrarenal } \\
\text { vascular beds, prostate cancer, autonomic nervous } \\
\text { system cells }\end{array}$ & Regulation of blood pressure by renin \\
\hline
\end{tabular}

Abbreviations: DCs, dendritic cells; GLP-I, glucagon-like peptide I; HDL, high density lipoprotein; PYY, peptide YY; SCFAs, short-chain fatty acids; Treg, regulatory T cells. 
energy metabolism, evoking hormone release, and regulating immune inflammation and blood pressure.

\section{Energy metabolism}

Locally, SCFAs (butyrate preferentially) are used as fuel for colonocytes and in the maintenance of the epithelium. ${ }^{7}$ After absorption into the bloodstream, ${ }^{17}$ circulatory SCFAs act as a primary substrate for hepatic and adipocyte lipogenesis, as well as for intestinal gluconeogenesis, and exhibit a range of metabolic effects (Figure 1) ${ }^{38,39}$ For example, SCFAs activate AMP-activated protein kinases (AMPK) in the liver and muscle, thereby triggering the activation of peroxisome proliferator-activated receptors, and thus stimulating glucose uptake and fatty acid oxidation and improving glycemic control, at least in murine models. ${ }^{40}$

Several studies reported the benefits of regulating lipid or glucose metabolism by resistant starch, which increased
SCFAs production ${ }^{41,42}$ or fecal transplantation of butyrateproducing bacteria. ${ }^{43,44}$ Administration of acetate or propionate in adipocytes of mice reduced plasma free fatty acid levels by enhancing adipogenesis and inhibiting lipolysis via the activation of GPR 43. ${ }^{38,45-47}$ In obese hyperinsulinemia $\mathrm{fa} / \mathrm{fa}$ rats, propionate lowered urinary glucose excretion and fasting blood glucose levels. ${ }^{48}$ Amelioration of obesity and its comorbidities, as well as insulin resistance, was also observed in mice fed with dietary supplementation of acetate. ${ }^{40}$ Not only in an experimental setup, but also in clinical studies, overweight adults supplemented with inulin-propionate ester for a longer term (which could be metabolized by the microbiota in the colon to propionate) showed a significant reduction in weight gain via appetite regulation. ${ }^{49}$ Patients were advised to increase their dietary fibers, which increased concentrations of SCFAs in the gut and circulatory system; this was associated with the reduction of adverse consequences of hyperglycemia. ${ }^{50}$

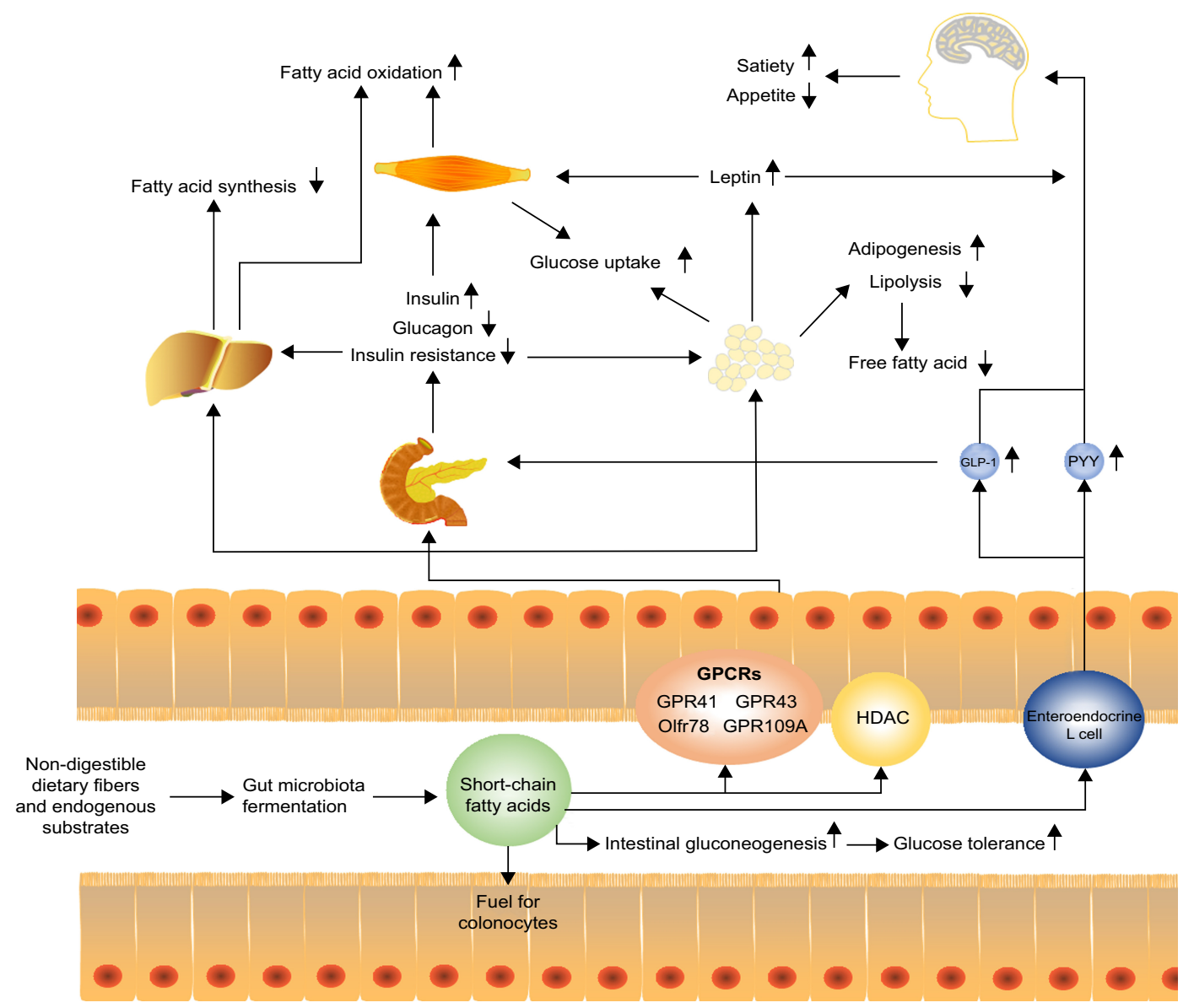

Figure I Short-chain fatty acids to host appetite and metabolism control. Short-chain fatty acids (SCFAs) produced via microbiota fermentation of non-digestible dietary fibers or endogenous substrates can be used as fuel for colonocytes and stimulate intestinal gluconeogenesis, which improves glucose tolerance. Moreover, SCFAs can stimulate enteroendocrine $L$ cells to release anorexigenic hormones PYY and GLP-I. These hormones promote satiety and suppress appetite which may promote weight loss. GLP-I increases the production of insulin and decreases the production of glucagon in the pancreas, which then increases the uptake of glucose in muscle and adipose tissues. SCFAs can also decrease fatty acid synthesis and promote fatty acid oxidation in the liver. In adipose tissue, SCFAs can increase adipogenesis and inhibit lipolysis, thereby decreasing free fatty acids. Meanwhile, SCFAs can promote the secretion of leptin that suppresses appetite. Abbreviations: GLP-I, glucagon-like peptide I; GPCRs, G protein-coupled receptors; HDAC, histone acetylation; PYY, peptide YY. 
The benefits of SCFAs on energy metabolism could be partially explained by modulating the secretion of hormones such as peptide YY (PYY), glucagon-like peptide 1 (GLP-1), and leptin by activating GPR41 and GPR43. 48,51,52 PYY, a gut hormone derived from enteroendocrine cells, could suppress postprandial appetite, slow gastrointestinal motility, decrease insulin secretion and sensitivity, and increase glucose uptake by SCFAs-stimulated GPR $41 .^{38,53-55}$ In contrast, GLP-1 influences peripheral metabolic effects by stimulating insulin secretion and increasing glucose tolerance. Further, GLP-1 exerts cardioprotective effects and induces beta-cell proliferation and plays a major role in decreasing epithelial permeability and increasing mucosal antibacterial defenses by GPR41 and GPR43 activation. ${ }^{56-60}$ SCFA-induced leptin is involved in regulating appetite and energy metabolism by GPCRs activation; ${ }^{45}$ failure of leptin regulation is connected with obesity, hyperphagia, infertility, and immunological defects. ${ }^{61}$ In general, SCFA-activated GPR 41 or GPR 43 promotes hormone secretion that inhibits gastric emptying and food intake and further modulates metabolic functions both locally in the gut and distally at peripheral tissues to remain systemic in metabolic health. However, a recent study in rats showed contradictory results - acetate-induced obesity and insulin resistance. ${ }^{62}$ Also, SCFA concentrations were found to be higher in feces of obese humans when compared to lean controls. ${ }^{63}$ This suggests that more studies are required to elucidate the true functions of SCFAs in regulating energy metabolism.

\section{Inflammation and immune regulation}

Kidney disease is often related to microinflammation and dysbiosis of immune system. Although the detailed mechanisms by which the gut microbiota regulates host health and renal health have yet to be elucidated, gut microbiota-generated SCFAs, at least partly, mediate inflammatory and immune effects (Figure 2).

SCFAs modulate inflammation both in intestinal and in extra-intestinal environments via leukocyte recruitment and chemokines production. The anti-inflammatory effects of SCFAs have been well characterized at both the epithelial and immune cell levels. On one hand, SCFAs are involved in the expression of adhesion molecules in neutrophils and endothelial cells that reduce cell recruitment. On the other hand, SCFAs exert anti-inflammatory effects by suppressing the production of cytokines such as interleukin (IL)-6, IL-1 $\beta$, tumor necrosis factor- $\alpha$, and nitric oxide, ${ }^{64}{ }^{69}$ and/or by increasing the production of anti-inflammatory cytokine IL- $10^{70}$ via stimulation of GPCRs ${ }^{58,71,72}$ or inhibition of HDAC. ${ }^{73}$
Moreover, SCFAs induce IL-10-expressing regulatory $\mathrm{T}$ cells to reduce inflammation. ${ }^{74-77}$ SCFAs also stimulate the migration of neutrophils by chemotaxis via activation of GPR43, which further leads to inflammatory responses. . $278,79^{2}$ In clinical investigation and animal models, SCFAs have also been demonstrated to possess protective effects on inflammatory bowel conditions, allergic airway disease, and CKD, due to their inhibitory effects on pro-inflammatory cytokines and reactive oxygen species. . $^{37,80,81}$

The generation of SCFAs was also confirmed to influence innate immunity and adaptive immunity. For innate immunity, low concentrations of butyrate stimulate intestinal epithelial cells (goblet cells) to release mucin Muc2, which enhances the gut barrier function and heightens the response to pathogens and commensal bacteria, while high concentrations of butyrate diminish the intestinal barrier function. ${ }^{82}$ In terms of adaptive immune system, it was illustrated that the number of colonic Tregs are influenced, or even determined, by the luminal concentration of SCFAs through GPCRs or epigenetic modification-inhibition of HDAC..$^{29,59,74-77,83-85}$ In general, Tregs stimulated by SCFAs always decrease inflammation under certain conditions; SCFAs induce Th1 and Th17 lymphocytes production ${ }^{35,74}$ by cellular bioenergetic metabolism via the conversion of SCFAs to acetyl-CoA, integration into the tricarboxylic acid, and subsequent activation of mTOR. ${ }^{86}$ SCFAs also indirectly affect T-cell differentiation patterns by exerting a broadly immunosuppressive or tolerogenic effect on antigen-presenting cells. For example, SCFAs inhibit the development of myeloid dendritic cells (DCs) from their progenitors, ${ }^{87}$ as well as their functional maturation, ${ }^{88,89}$ which then limits their ability to present antigens and cytokines to make effector T cells..$^{35}$ Further, SCFAs act on DCs to suppress the expression of $\mathrm{T}$ cell-activating molecules such as major histocompatibility complex II molecules, costimulatory molecules, and cytokines leading to generation of tolerogenic $\mathrm{T}$ cells rather than inflammatory $\mathrm{T}$ cells. ${ }^{35,37}$ The tolerogenic effect of SCFAs on DCs could lower inflammatory responses. Although SCFAs mostly regulate the immune system to decrease inflammation, the activity of SCFAs in immune and epithelial cells may boost inflammatory responses, if not properly regulated. ${ }^{35}$ Thus, the function of SCFAs still seems to be inconsistent and complex, and future studies could provide mechanistic insights into how gut microbiota-derived metabolites contribute to immune inflammation.

In addition, SCFAs exhibit apparent impacts on cell differentiation, oxidative DNA damage, and apoptosis death through autophagy..$^{18,90-92}$ SCFAs could modulate blood pressure by regulating renin release and peripheral resistance 


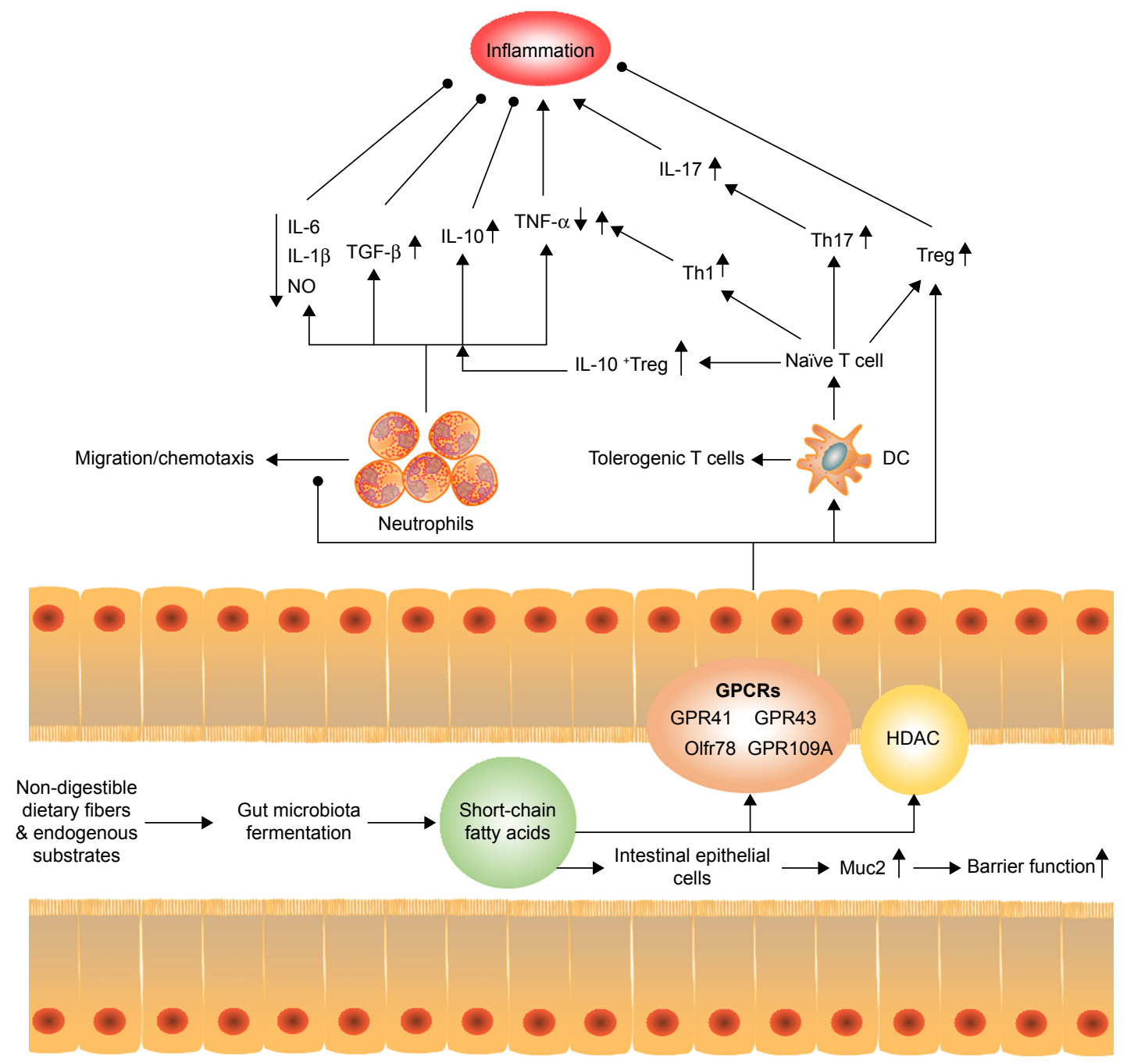

Figure 2 Regulation of short-chain fatty acids to host inflammation and immune. SCFAs can stimulate intestinal epithelial cells to release Muc2, which enhance the gut barrier function and heighten the response to pathogens and commensal bacteria. Moreover, SCFAs can reduce the recruitment of neutrophils under certain condition, with an increase in the levels of TGF- $\beta$, IL-I0 and a decrease in the levels of IL-6, IL-I $\beta$, NO, and TNF- $\alpha$ to inhibit inflammation. Meanwhile, SCFAs promote T-cell production of IL-I 0 and Treg to prevent inflammatory responses. On the other hand, SCFAs act on DCs to limit the expression of T cell-activating molecules such as MHC II molecules and costimulatory molecules, leading to the generation of tolerogenic T cells rather than inflammatory T cells. The tolerogenic effect of SCFAs on DCs can lower inflammatory responses. However, the direct effect of SCFAs on T cells enhances the generation of ThI and ThI7 cells to boost immunity to fight pathogens, which means that activation of SCFAs for immune cells and epithelial cells may increase inflammatory responses, if not properly regulated.

Abbreviations: DCs, dendritic cells; FAs, short-chain fatty acids; GPCRs, G protein-coupled receptors; HDAC, histone acetylation; NO, nitrous oxide; TGF- $\beta$, transforming growth factor- $\beta$; TNF- $\alpha$, tumor necrosis factor- $\alpha$.

via Olfr78 and Gpr41 expressed on the afferent arteriole (juxtaglomerular apparatus) and smooth-muscle cells of the small resistance vessels. ${ }^{93-95}$ So, the functions of SCFAs in most parts are contradictory; it is now becoming clear that gut microbiota-derived metabolites play a central role in host physiology. ${ }^{96}$

\section{SCFAs in kidney diseases}

In recent years, considerable studies have explored a new and exciting area: the interaction between the gut microbiome and kidney disease, and have reported that alteration of intestinal microbiota in CKD is an important indicator of impaired renal function and progression of CKD. ${ }^{97}$ Kidney disease is often related to malnutrition, hypertension or hypotension, microinflammation, dysbiosis of immune system, and multiple oxidative stress, which could be reversed by SCFAs (Figure 3). Furthermore, growing evidence has highlighted that SCFAs exhibited positive effects on kidney disease in both experimental animals and patients.

\section{Clinical investigations of gut microbiota-derived SFCAs}

Recently, multiple studies focusing on microbiota in CKD or end-stage renal disease (ESRD) patients have reported a 


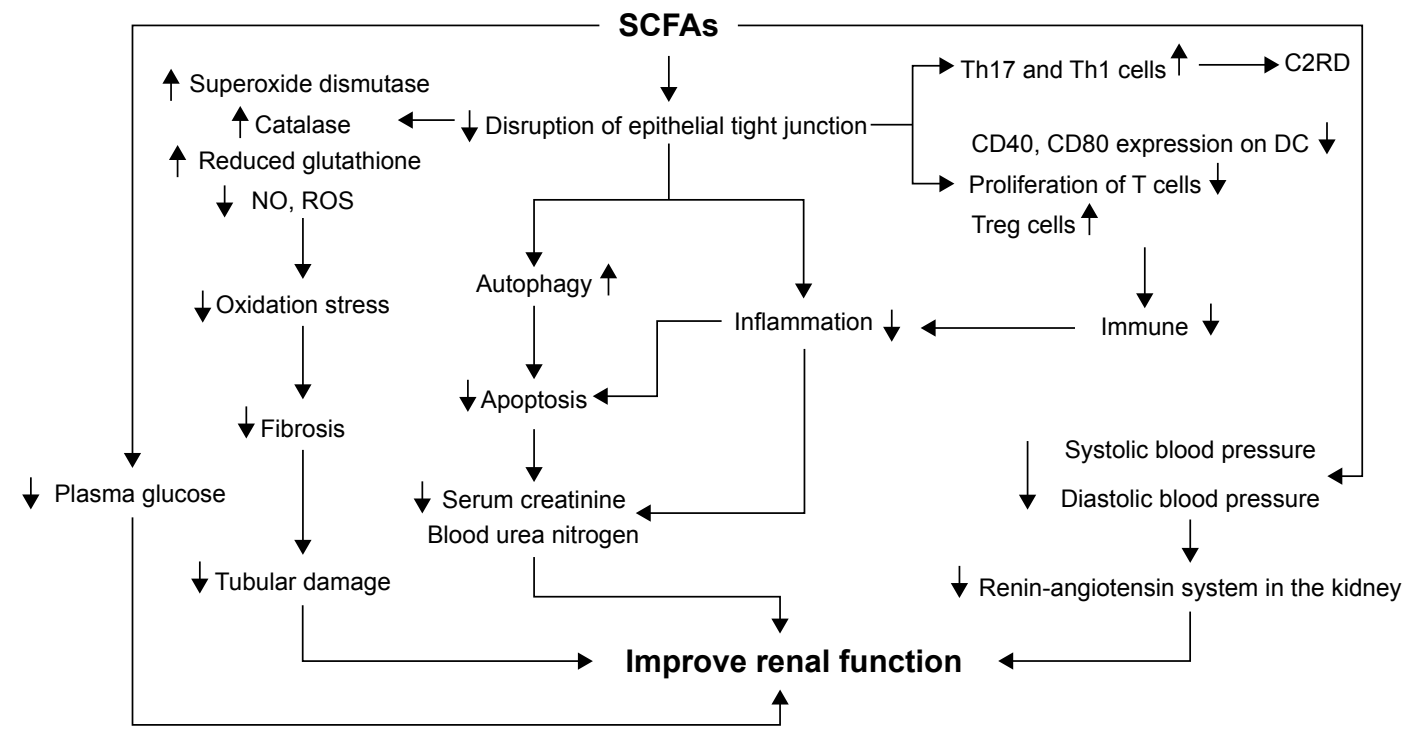

Figure 3 Regulation of short-chain fatty acids to improve kidney function SCFAs can decrease the disruption of epithelial tight junction. After getting absorbed in blood, SCFAs can suppress oxidation stress by increasing superoxide dismutase, catalase, and reduced glutathione, and by decreasing nitric oxide (NO) and reactive oxygen species (ROS), which can lead to the decline of renal fibrosis and amelioration of tubular damage. In addition, SCFAs can also inhibit apoptosis by promoting autophagy and suppressing inflammation by regulating immune system, thereby decreasing serum creatine as well as blood urea nitrogen to improve renal function. Regulation of SCFAs on blood pressure and plasma glucose may help to ameliorate renal function in chronic kidney diseases. However, SCFAs can also increase ThI7 and ThI cells to promote acetate- or C2-induced renal disease (C2RD) under certain condition, as the negative outcomes of SCFAs on kidney.

Abbreviation: SCFAs, short-chain fatty acids.

correlation between dysbiosis and CKD. ${ }^{7,98}$ Compared with control groups, patients with CKD or ESRD have altered microbiota ${ }^{99}$ with increased bacteria that possessed urease, uricase, p-cresol-, and indole-forming enzymes and reduced bacteria that possessed SCFA-forming enzymes. ${ }^{100}$ Uremic toxicities produced by microbiota could not only worsen the intestinal environment and alter its composition, but also affect cardiovascular disease progression and mortality in patients with CKD and ESRD. ${ }^{101-105}$ For treatment of these toxicities, dietary fiber supplementation in a group of chronic hemodialysis patients was reported to reduce serum concentration of indoxyl sulfate and p-cresol sulfate, ${ }^{106}$ and the use of indoxyl sulfate-binding agent, AST-120, in predialysis CKD patients also improved uremic symptoms, enhanced 5-year survival rate, and potentially delayed the onset of uremia. ${ }^{107,108}$ Compared to gut microbiota-generated toxicities, there were few studies that focused on SCFAs in $\mathrm{CKD} / \mathrm{ESRD}$ patients, and most studies were related to dietary management. For instance, in ESRD patients, reduced dietary fiber intake was associated with a reduction in the population of butyrate-forming bacteria, ${ }^{100}$ and after improving dietary management, colonic-CKD pathology ameliorated. ${ }^{109}$ On the whole, these observations suggest the potentially beneficial effects of fiber-rich diets on CKD progression. However, despite indirect positive effects of SCFAs on remission of $\mathrm{CKD} / \mathrm{ESRD}$, direct effects on kidney diseases are still in the experimental stage and require further study.

\section{Experimental studies of SFCAs in animals}

In recent decades, a small but growing number of animal experiments focusing on SCFAs in kidney disease have been reported using different models. However, these are mainly divided into two parts: acute kidney injury (AKI) and CKD (Table 2).

\section{AKI}

Regarding AKI, researchers have expanded the role of acetate to explain the gut-kidney connection in several animal models, including ischemia-reperfusion injury, contrastinduced nephropathy (CIN), and gentamicin-induced nephrotoxicity. Though various mechanisms were reported, most of these studies suggest that decreasing inflammation and enhancing antioxidant activity by SCFAs may result in the improvement of renal function.

In the ischemia-reperfusion injury model, treatment with acetate or acetate-producing bacteria could reduce kidney injury. ${ }^{2}$ The key mechanism of action of SCFAs against kidney injury was suggested to be the reduction of inflammatory cytokines and chemokines locally and systemically, as well as the inhibition of production of reactive oxygen species (ROS), apoptosis, and chromatin modification. ${ }^{2}$ It is also interesting to note that in the ischemia-reperfusion models of other tissues, $\mathrm{SCFAs}^{1}$ or SCFA-producing bacteria ${ }^{110}$ have been shown to exhibit protective effects, implying that the underlying mechanism may be common across tissues. 
Table 2 Applications of SCFAs in animal models of kidney injury

\begin{tabular}{|c|c|c|c|}
\hline Diseases & Administration & Effect of SCFAs on disease models & References \\
\hline \multicolumn{4}{|l|}{ AKI } \\
\hline Ischemia & $\mathrm{C} 2, \mathrm{C} 3$, and $\mathrm{C} 4$ & Improve renal function & 2 \\
\hline reperfusion injury & $\begin{array}{l}\text { C2-producing } \\
\text { bacteria }\end{array}$ & $\begin{array}{l}\text { Decrease local and systemic inflammation, oxidative cellular stress, cell } \\
\text { infiltration/activation } \\
\text { Decrease apoptosis and increase autophagy } \\
\text { Decrease HDACs activity } \\
\text { Modulate chromatin modification enzymes }\end{array}$ & \\
\hline $\begin{array}{l}\text { Contrast-induced } \\
\text { nephrotoxicity }\end{array}$ & $\mathrm{C} 4$ & 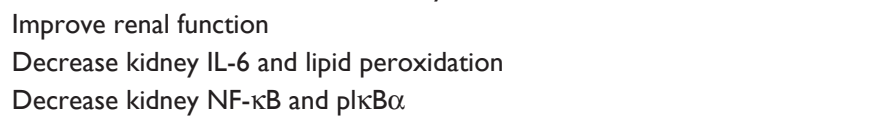 & 111 \\
\hline $\begin{array}{l}\text { Gentamicin-induced } \\
\text { nephrotoxicity }\end{array}$ & $\mathrm{C} 4$ & $\begin{array}{l}\text { Improve renal function } \\
\text { Improve body weight and food and water intake } \\
\text { Increase superoxide dismutase, catalase, and reduced glutathione } \\
\text { Increase inducible prohibitin }\end{array}$ & 112 \\
\hline $\begin{array}{l}\text { Ureteritis and } \\
\text { hydronephrosis }\end{array}$ & $\mathrm{C} 2, \mathrm{C} 3$, and $\mathrm{C} 4$ & $\begin{array}{l}\text { All major SCFAs have acetate- or C2-induced renal disease (C2RD) activity } \\
\text { Develop inflammatory responses and hyperplasia leading to ureteral } \\
\text { obstruction } \\
\text { Increase inflammatory ThI7 and ThI cells } \\
\text { Gpr } 4 \text { I-I- and Gpr } 43-\text { I- mice also develop C2RD }\end{array}$ & 117 \\
\hline \multicolumn{4}{|l|}{ CKD } \\
\hline $\begin{array}{l}\text { Diabetic } \\
\text { nephropathy }\end{array}$ & $\mathrm{C} 4$ & $\begin{array}{l}\text { Improve renal function } \\
\text { Decrease plasma glucose } \\
\text { Decrease fibrosis and collagen deposition } \\
\text { Decrease apoptosis } \\
\text { Decrease HDACs activity } \\
\text { Decrease activation of NF- } \mathrm{KB} \text { and DNA damage }\end{array}$ & 115 \\
\hline $\begin{array}{l}\text { Chronic kidney } \\
\text { disease }\end{array}$ & High-fiber diet & $\begin{array}{l}\text { Improve renal function } \\
\text { Decrease inflammation } \\
\text { Decrease oxidative stress } \\
\text { Decrease disruption of colonic epithelial tight junction } \\
\text { Decrease nuclear factor erythroid 2-related factor } 2 \text { (Nrf2) } \\
\text { Decrease activation of NF-KB }\end{array}$ & 80 \\
\hline $\begin{array}{l}\text { DOCA-salt } \\
\text { hypertensive }\end{array}$ & $\begin{array}{l}\text { High-fiber diet } \\
\text { C2 }\end{array}$ & $\begin{array}{l}\text { Decrease systolic blood pressure and diastolic blood pressure, cardiac } \\
\text { fibrosis and left ventricular hypertrophy } \\
\text { Decrease renal fibrosis } \\
\text { Downregulate cardiac and renal Egr I } \\
\text { Downregulate renin-angiotensin system in the kidney and MAPK signaling } \\
\text { in the heart }\end{array}$ & 116 \\
\hline Normal & $\mathrm{C} 2, \mathrm{C} 3$, and $\mathrm{C} 4$ & $\begin{array}{l}\text { C4 decreases pro-inflammatory cytokine } \\
\text { C3/C4 increase Treg cells }\end{array}$ & 75 \\
\hline
\end{tabular}

Abbreviations: AKI, acute kidney injury; CKD, chronic kidney disease; HDAC, histone acetylation; IL, interleukin; MAPK, mitogen-activated protein kinase; NF-KB, nuclear factor- $\kappa B$; SCFAs, short-chain fatty acids.

CIN is another form of AKI with exposure contrasting that of the media. A study showed that sodium butyrate protected against kidney injury by inhibiting inflammatory and oxidative tubular damage, with nuclear factor- $\kappa \mathrm{B}$ signal pathway playing key roles in the development of CIN.${ }^{111}$ However, the study did not exclude other potential mechanisms by which SCFAs may take part in inflammatory response, such as inhibition of HDAC, given that the regulatory mechanisms of SCFAs are extremely complex.

The effect of acute and chronic treatment of sodium butyrate in gentamicin-induced nephrotoxicity was also assessed. In an animal experimental model, kidney injury was attenuated by long-term oral administration of sodium butyrate via enhanced renal antioxidant enzymes activity, which promoted the expression of prohibitin protein ${ }^{112}$ and increased the levels of superoxide dismutase, catalase activity, and reduced glutathione. ${ }^{33}$ Another drug-induced nephropathy, paracetamol-induced nephrotoxicity, was reported to be protected by ethyl acetate extract of Zingiber zerumbet rhizome. This process was also probably mediated by its antioxidant properties. ${ }^{113}$

Taking into account all of these recent studies, they have almost included all main types of AKI experimental models and have shown the positive effects of acetate or butyrate to 
improve renal function. Although the results are exciting, they are still not sufficient to drop the veil of SCFAs, and the underlying mechanism still remains unclear; therefore, more studies are that focus on SCFAs are needed.

\section{CKD}

Supposing that SCFAs play a significant role in AKI, it might be of interest to define their role in the development and progression of CKD. Increasing dietary fiber in CKD rats showed similar results to clinical research, with significantly improved intestinal epithelial tight junctions, reduced oxidative stress and inflammation, and less severe renal dysfunction. ${ }^{80}$ Besides increasing SCFAs in uremic rats could improve kidney function, and neutralizing bacteria-derived uremic toxin indoxyl sulfate inside the gut could also delay the progression of CKD and cardiovascular disease. ${ }^{114}$ The direct effects of SCFAs on kidney disease have been studied in juvenile diabetic rats by administering butyrate posttreatment; the results showed that SCFAs not only decreased plasma glucose, creatinine, and urea but also improved renal histological alterations (including fibrosis and collagen deposition), apoptosis, and DNA damage. ${ }^{115}$ Supplementation of acetate was reported to attenuate glomerular and tubulointerstitial fibrosis in the DOCA-salt mice. ${ }^{116}$

However, there are still several negative outcomes of SCFAs on kidney injury. After chronically increasing oral doses of SCFAs to higher than physiological levels in mice, Th1 and Th17 cells were observed to generate in the ureteropelvic junction and proximal part of the ureter, which induced inflammation and led to kidney hydronephrosis, hereafter called acetate- or $\mathrm{C} 2$-induced renal disease (C2RD). ${ }^{117}$ It was indicated that $\mathrm{C} 2 \mathrm{RD}$ was not conducted by GPR41/GPR 43, ${ }^{117}$ but the underlying mechanism is still not clear. However, SCFAs were confirmed to play a dual role in the inflammation system depending on the stimulus concentration in kidney disease, consistent with the aforementioned inflammation of SCFAs. Besides C2RD, mice fed a high-fiber diet had increased gut butyrate and were more susceptible to infection with Escherichia coli, ${ }^{118}$ as well as enhanced Gb3 levels in the gut and kidney, which resulted in severe kidney damage. ${ }^{119}$

Despite growing interest in SCFAs, many problems involving chronic kidney injury have not yet been answered and are still disputed. Unlike the positive effects of SCFAs on AKI models that have been observed, the influence of SCFAs on CKD seems to be more controversial. This enhances the importance of SCFAs concentrations when testing the benefits of SCFAs in kidney disease and encourages further studies to identify the pharmacological concentration. Importantly, the benefits of SCFAs on diabetic nephropathy, the leading cause of ESRD worldwide, should be paid more attention to, because of the positive effects of SCFAs on regulation of energy metabolism and immune inflammation.

\section{Experimental studies of SFCAs in kidney cells}

Researchers have explored not only the in vivo effects of SCFAs but also their mechanism of action on kidney cells (Table 3). When glomerular mesangial cells (GMCs) are induced by high glucose and lipopolysaccharide (LPS),

Table 3 Applications of SCFAs in different kidney cells

\begin{tabular}{|c|c|c|c|c|}
\hline Diseases & Cell types & Cell administration & Effects & References \\
\hline $\begin{array}{l}\text { AKI induced } \\
\text { by IRI }\end{array}$ & $\begin{array}{l}\text { BM-DCs } \\
\text { HK-2 cells }\end{array}$ & $\mathrm{C} 2, \mathrm{C} 3$, and $\mathrm{C} 4$ & $\begin{array}{l}\text { Decrease BM-DCs activation, APC function, NF- } \mathrm{KB} \\
\text { activation and nitric oxide production, ROS production } \\
\text { Inhibit HIF-I } \alpha \text { translocation to the nucleus, lactate } \\
\text { production, and VEGF expression under hypoxia }\end{array}$ & 2 \\
\hline $\begin{array}{l}\text { Ureteritis and } \\
\text { hydronephrosis }\end{array}$ & Renal T cells & $\mathrm{C} 2, \mathrm{C} 3, \mathrm{C} 4$ & Rapamycin decreases $T$ cells & 117 \\
\hline $\begin{array}{l}\text { Diabetic } \\
\text { nephropathy }\end{array}$ & GMCs & $\begin{array}{l}\text { C2, C3, C4 } \\
\text { GPR43 agonist }\end{array}$ & $\begin{array}{l}\text { Inhibit GMCs proliferation } \\
\text { Decrease inflammation } \\
\text { Decrease ROS and oxidative stress } \\
\text { Decrease ICAM-I }\end{array}$ & 121 \\
\hline Normal & HK-2 cells & $\begin{array}{l}\text { Dietary supplementation } \\
\text { with gum arabic } \\
\text { (SUPERGUM) }\end{array}$ & $\begin{array}{l}\text { C4 decreases TGF- } \beta \text { I generation and } \\
\text { TGF- } \beta \text { I-dependent signaling }\end{array}$ & 122 \\
\hline Normal & $\begin{array}{l}\text { CD4+ T cells } \\
\text { CDIIc+ DCs } \\
\text { Foxp3 induction }\end{array}$ & $\mathrm{C} 4$ & $\begin{array}{l}\text { Decrease pro-inflammatory cytokine } \\
\text { Increase Treg induction }\end{array}$ & 75 \\
\hline Normal & Porcine kidney cells & $\mathrm{C} 4$ & Upregulate WTI expression & 127 \\
\hline
\end{tabular}

Abbreviations: APC, antigen presenting cells; BM-DCs, bone marrow dendritic cells; GMCs, glomerular mesangial cells; HIF-I $\alpha$, hypoxia inducible factor-I $\alpha$; HK-2 cells, epithelial kidney cell line; ICAM-I, intercellular adhesion molecule-I; ROS, reactive oxygen species; SCFAs, short-chain fatty acids; TGF- $\beta$ I, transforming growth factor- $\beta$ I; VEGF, vascular endothelial cell growth factor; WTI, Wilms tumor I. 
the pharmacological concentrations of SCFAs accompanied with GPR43 agonist diminish renal inflammation by decreasing MCP-1 and IL-1 $\beta$. Inflammation and oxidative stress are inseparably linked, as each causes and strengthens the other, which could cause glomerulosclerosis, tubular atrophy, and fibrosis. ${ }^{120}$ Therefore, besides decreasing inflammation, SCFAs inhibit ROS generation induced by high glucose and LPS in $\mathrm{GMCs}^{121}$ and HK-2 human kidney epithelial cells after hypoxia. ${ }^{2}$ In addition to GMCs, elevated concentration of butyrate in proximal tubular epithelial cells was described to prevent TGF- $\beta 1$ generation, ${ }^{122}$ which is involved in renal fibrosis, and its antagonistic action has been proposed as a potential therapeutic target. ${ }^{123-125}$ In porcine kidney fibroblast, WT1, involved in cell proliferation and development, was markedly enhanced along with an increase in sodium butyrate levels and by prolonging the treatment. ${ }^{126,127}$

These investigations of SCFAs on kidney resident cells (glomerular cells and tubular cells), which concentrate on inflammation, ROS, and fibrosis, are in agreement with the findings from animal experiments and provide more potential pathways to understand the mechanisms. However, future studies are still required to focus more on the interaction among SCFAs-associated molecular patterns and metabolism, inflammation, and immune system in order to clarify the molecular mechanisms behind kidney injury in the pathogenesis of kidney disease.

\section{Conclusion}

In summary, the function of gut microbiota-derived SCFAs in kidney disease has become an exciting area in recent years. SCFAs play extensive roles in host physiology, such as regulation of energy metabolism, immune inflammation, and blood pressure by recognizing their receptors and inhibiting HDACs. However, the entire field of SCFAs in kidney disease is still in its infancy. It has now been reported that the main beneficial effects of SCFAs on kidney function were by decreasing inflammation and enhancing antioxidant activity. Nevertheless, there are still few related studies, and all the concerned studies are either preliminary or controversial. Thus, in coming years, more explorations will be needed to better understand these pathways and their potential implications.

\section{Acknowledgments}

The authors thank Steve Salerno, from the University of Michigan, for proofreading the manuscript and for their language support, which improved the presentation of the work. This study was supported by the National Key Research and Development Program of China (No 2016YFC1305403).

\section{Disclosure}

The authors declare that the research was conducted in the absence of any commercial or financial relationships that could be construed as potential conflicts of interest in this work.

\section{References}

1. Aguilar-Nascimento JE, Salomao AB, Nochi RJ Jr, Nascimento M, Neves Jde $S$. Intraluminal injection of short chain fatty acids diminishes intestinal mucosa injury in experimental ischemia-reperfusion. Acta Cir Bras. 2006;21(1):21-25.

2. Andrade-Oliveira V, Amano MT, Correa-Costa M, et al. Gut bacteria products prevent AKI induced by ischemia-reperfusion. $J$ Am Soc Nephrol. 2015;26(8):1877-1888.

3. Bindels LB, Porporato P, Dewulf EM, et al. Gut microbiota-derived propionate reduces cancer cell proliferation in the liver. Br J Cancer. 2012;107(8):1337-1344.

4. Vaziri ND, Zhao YY, Pahl MV. Altered intestinal microbial flora and impaired epithelial barrier structure and function in CKD: the nature, mechanisms, consequences and potential treatment. Nephrol Dial Transpl. 2016;31(5):737-746.

5. Vaziri ND, Yuan J, Norris K. Role of urea in intestinal barrier dysfunction and disruption of epithelial tight junction in chronic kidney disease. Am J Nephrol. 2013;37(1):1-6.

6. Moraes C, Fouque D, Amaral AC, Mafra D. Trimethylamine N-oxide from gut microbiota in chronic kidney disease patients: focus on diet. J Ren Nutr. 2015;25(6):459-465.

7. Ramezani A, Massy ZA, Meijers B, Evenepoel P, Vanholder R, Raj DS Role of the gut microbiome in uremia: a potential therapeutic target. Am J Kidney Dis. 2016;67(3):483-498.

8. Diaz Heijtz R, Wang S, Anuar F, et al. Normal gut microbiota modulates brain development and behavior. Proc Natl Acad Sci U S A. 2011; 108(7):3047-3052.

9. Vijay-Kumar M, Aitken JD, Carvalho FA, et al. Metabolic syndrome and altered gut microbiota in mice lacking Toll-like receptor 5. Science. 2010;328(5975):228-231.

10. Uronis JM, Muhlbauer M, Herfarth HH, Rubinas TC, Jones GS, Jobin C. Modulation of the intestinal microbiota alters colitis-associated colorectal cancer susceptibility. PLoS One. 2009;4(6):e6026.

11. Paola MD, Filippo CD, Cavalieri D, et al. Impact of diet in shaping gut microbiota revealed by a comparative study in children from Europe and rural Africa. Proc Natl Acad Sci U S A. 2010;107(33):14691.

12. Lin MY, de Zoete MR, van Putten JP, Strijbis K. Redirection of epithelial immune responses by short-chain fatty acids through inhibition of histone deacetylases. Front Immunol. 2015;6:554.

13. Kendle M, Maslowski. The role of GPR43 in the immune system: a novel connection between diet, gut microbiota and immune function. Available from: Unsworks.unsw.edu.au. Accessed September 1, 2017.

14. Nyman M. Fermentation and bulking capacity of indigestible carbohydrates: the case of inulin and oligofructose. Br J Nutr. 2002;87(Supp1 2): S163-S168.

15. Kotzampassi K, Giamarellosbourboulis EJ, Stavrou G. Obesity as a consequence of gut bacteria and diet interactions. ISRN Obes. 2014; 2014(196):651895.

16. Wong JM, de Souza R, Kendall CW, Emam A, Jenkins DJ. Colonic health: fermentation and short chain fatty acids. J Clin Gastroenterol. 2006;40(3):235-243.

17. Pomare EW, Branch WJ, Cummings JH. Carbohydrate fermentation in the human colon and its relation to acetate concentrations in venous blood. J Clin Invest. 1985;75(5):1448-1454.

18. Adom D, Nie D. Regulation of autophagy by short chain fatty acids in colon cancer cells. In: Bailly Y, editor. Autophagy - A Double-Edged Sword - Cell Survival or Death? InTech; 2013.

19. Orrhage K, Nord CE. Factors controlling the bacterial colonization of the intestine in breastfed infants. Acta Paediatr. 1999;88(430):47-57. 
20. Koh A, De Vadder F, Kovatcheva-Datchary P, Backhed F. From dietary fiber to host physiology: short-chain fatty acids as key bacterial metabolites. Cell. 2016;165(6):1332-1345.

21. Ulven T. Short-chain free fatty acid receptors FFA2/GPR43 and FFA3/GPR41 as new potential therapeutic targets. Front Endocrinol. 2012;3:111.

22. Dewulf EM, Ge Q, Bindels LB, et al. Evaluation of the relationship between GPR43 and adiposity in human. Nutr Metabol. 2012; 10(1):11.

23. Tang Y, Chen Y, Jiang H, Robbins GT, Nie D. G-protein-coupled receptor for short-chain fatty acids suppresses colon cancer. Int $J$ Cancer. 2011;128(4):847-856

24. Karaki S, Mitsui R, Hayashi H, et al. Short-chain fatty acid receptor, GPR43, is expressed by enteroendocrine cells and mucosal mast cells in rat intestine. Cell Tissue Res. 2006;324(3):353-360.

25. Nilsson NE, Kotarsky K, Owman C, Olde B. Identification of a free fatty acid receptor, FFA2R, expressed on leukocytes and activated by short-chain fatty acids. Biochem Biophys Res Commun. 2003;303(4): 1047-1052.

26. Pluznick JL, Protzko RJ, Gevorgyan H, et al. Olfactory receptor responding to gut microbiota-derived signals plays a role in renin secretion and blood pressure regulation. Proc Natl Acad Sci U S A. 2013; 110(11):4410-4415.

27. Vinolo MA, Rodrigues HG, Nachbar RT, Curi R. Regulation of inflammation by short chain fatty acids. Nutrients. 2011;3(10):858-876.

28. Flegel C, Manteniotis S, Osthold S, Hatt H, Gisselmann G. Expression profile of ectopic olfactory receptors determined by deep sequencing. PLoS One. 2013;8(2):e55368.

29. Singh N, Gurav A, Sivaprakasam S, et al. Activation of Gpr109a, receptor for niacin and the commensal metabolite butyrate, suppresses colonic inflammation and carcinogenesis. Immunity. 2014;40(1): $128-139$.

30. Thangaraju M, Cresci GA, Liu K, et al. GPR109A is a G-proteincoupled receptor for the bacterial fermentation product butyrate and functions as a tumor suppressor in colon. Cancer Res. 2009;69(7): 2826-2832.

31. Wanders D, Graff EC, Judd RL. Effects of high fat diet on GPR109A and GPR81 gene expression. Biochem Biophys Res Commun. 2012; 425(2):278-283.

32. Ingersoll MA, Potteaux S, Alvarez D, Hutchison SB, Van RN, Randolph GJ. Niacin inhibits skin dendritic cell mobilization in a GPR109A independent manner but has no impact on monocyte trafficking in atherosclerosis. Immunobiology. 2012;217(5):548-557.

33. Huang W, Zhou L, Guo H, Xu Y, Xu Y. The role of short-chain fatty acids in kidney injury induced by gut-derived inflammatory response. Metabolism. 2017;68:20-30.

34. Tan J, McKenzie C, Potamitis M, Thorburn AN, Mackay CR, Macia L. The role of short-chain fatty acids in health and disease. Adv Immunol. 2014;121:91-119.

35. Kim CH, Park J, Kim M. Gut microbiota-derived short-chain fatty acids, $\mathrm{T}$ cells, and inflammation. Immune Netw. 2014;14(6):277-288.

36. Maslowski KM, Vieira AT, Ng A, et al. Regulation of inflammatory responses by gut microbiota and chemoattractant receptor GPR43. Nature. 2009;461(7268):1282-1286.

37. Trompette A, Gollwitzer ES, Yadava K, et al. Gut microbiota metabolism of dietary fiber influences allergic airway disease and hematopoiesis. Nat Med. 2014;20(2):159-166.

38. Yamashita H, Fujisawa K, Ito E, et al. Improvement of obesity and glucose tolerance by acetate in type 2 diabetic Otsuka Long-Evans Tokushima Fatty (OLETF) rats. Biosci Biotechnol Biochem. 2014;71(5): 1236-1243.

39. Berggren AM, Nyman EM, Lundquist I, Bjorck IM. Influence of orally and rectally administered propionate on cholesterol and glucose metabolism in obese rats. Br J Nutr. 1996;76(2):287-294.

40. Bouter KE, van Raalte DH, Groen AK, Nieuwdorp M. Role of the gut microbiome in the pathogenesis of obesity and obesity-related metabolic dysfunction. Gastroenterology. 2017;152(7):1671-1678.
41. Topping DL, Clifton PM. Short-chain fatty acids and human colonic function: roles of resistant starch and nonstarch polysaccharides. Physiol Rev. 2001;81(3):1031-1064.

42. Stoddart LA, Smith NJ, Milligan G. International Union of Pharmacology. LXXI. Free fatty acid receptors FFA1, -2 , and -3 : pharmacology and pathophysiological functions. Pharmacol Rev. 2008;60(4):405-417.

43. Vrieze A, Van Nood E, Holleman F, et al. Transfer of intestinal microbiota from lean donors increases insulin sensitivity in individuals with metabolic syndrome. Gastroenterology. 2012;143(4):913.e7-916.e7.

44. Udayappan SD, Hartstra AV, Dallinga-Thie GM, Nieuwdorp M. Intestinal microbiota and faecal transplantation as treatment modality for insulin resistance and type 2 diabetes mellitus. Clin Exp Immunol. 2014;177(1):24.

45. Zaibi MS, Stocker CJ, O'Dowd J, et al. Roles of GPR41 and GPR43 in leptin secretory responses of murine adipocytes to short chain fatty acids. FEBS Lett. 2010;584(11):2381-2386.

46. Hong YH, Nishimura Y, Hishikawa D, et al. Acetate and propionate short chain fatty acids stimulate adipogenesis via GPCR43. Endocrinology. 2005;146(12):5092-5099.

47. Ge H, Li X, Weiszmann J, et al. Activation of G protein-coupled receptor 43 in adipocytes leads to inhibition of lipolysis and suppression of plasma free fatty acids. Endocrinology. 2008;149(9):4519-4526.

48. Delzenne NM, Cani PD, Everard A, Neyrinck AM. Gut microorganisms as promising targets for the management of type 2 diabetes. Diabetologia. 2015;58(10):2206-2217.

49. Chambers ES, Viardot A, Psichas A, et al. Effects of targeted delivery of propionate to the human colon on appetite regulation, body weight maintenance and adiposity in overweight adults. Gut. 2015;64(11):1744-1754.

50. Park Y, Subar AF, Hollenbeck A, Schatzkin A. Dietary fiber intake and mortality in the NIH-AARP diet and health study. Arch Int Med. 2011; 171(12):1061-1068.

51. Tolhurst G, Heffron H, Lam YS, et al. Short-chain fatty acids stimulate glucagon-like peptide-1 secretion via the G-protein-coupled receptor FFAR2. Diabetes. 2012;61(2):364-371.

52. Rozengurt N, Wu SV, Chen MC, Huang C, Sternini C, Rozengurt E. Colocalization of the alpha-subunit of gustducin with PYY and GLP-1 in L cells of human colon. Am J Physiol Gastrointest Liver Physiol. 2006; 291(5):G792-G802.

53. Freeland KR, Wolever TM. Acute effects of intravenous and rectal acetate on glucagon-like peptide-1, peptide YY, ghrelin, adiponectin and tumour necrosis factor-alpha. Br J Nutr. 2010;103(3):460-466.

54. Plaisancié P, Dumoulin V, Chayvialle JA, Cuber JC. Luminal peptide YY-releasing factors in the isolated vascularly perfused rat colon. J Endocrinol. 1997;151(3):421-429.

55. Samuel BS, Shaito A, Motoike T, et al. Effects of the gut microbiota on host adiposity are modulated by the short-chain fatty-acid binding G protein-coupled receptor, Gpr41. Proc Natl Acad Sci U S A. 2008; 105(43):16767-16772.

56. Holst JJ. The physiology of glucagon-like peptide 1. Physiol Rev. 2007; 87(4):1409-1439.

57. Ross SA, Ekoe JM. Incretin agents in type 2 diabetes. Can Fam Physician. 2010;56(7):639-648.

58. Kim MH, Kang SG, Park JH, Yanagisawa M, Kim CH. Short-chain fatty acids activate GPR41 and GPR43 on intestinal epithelial cells to promote inflammatory responses in mice. Gastroenterology. 2013;145(2): 396-406.e1-e10.

59. Morris G, Berk M, Carvalho A, et al. The role of the microbial metabolites including tryptophan catabolites and short chain fatty acids in the pathophysiology of immune-inflammatory and neuroimmune disease. Mol Neurobiol. 2017;54(6):4432-4451.

60. Everard A, Cani PD. Gut microbiota and GLP-1. Rev Endocri Metab Disord. 2014;15(3):189-196.

61. Fujikawa T, Coppari R. Living without insulin: the role of leptin signaling in the hypothalamus. Front Neurosci. 2015;9:108.

62. Perry RJ, Peng L, Barry NA, et al. Acetate mediates a microbiome-brainbeta-cell axis to promote metabolic syndrome. Nature. 2016;534(7606): 213-217. 
63. Schwiertz A, Taras D, Schafer K, et al. Microbiota and SCFA in lean and overweight healthy subjects. Obesity. 2010;18(1):190-195.

64. Tedelind S, Westberg F, Kjerrulf M, Vidal A. Anti-inflammatory properties of the short-chain fatty acids acetate and propionate: a study with relevance to inflammatory bowel disease. World J Gastroenterol. 2007;13(20):2826-2832

65. Park JS, Lee EJ, Lee JC, Kim WK, Kim HS. Anti-inflammatory effects of short chain fatty acids in IFN-gamma-stimulated RAW 264.7 murine macrophage cells: involvement of NF-kappaB and ERK signaling pathways. Int Immunopharmacol. 2007;7(1):70-77.

66. Vinolo MA, Rodrigues HG, Hatanaka E, Sato FT, Sampaio SC, Curi R. Suppressive effect of short-chain fatty acids on production of proinflammatory mediators by neutrophils. J Nutr Biochem. 2011;22(9): 849-855.

67. Luhrs H, Gerke T, Muller JG, et al. Butyrate inhibits NF-kappaB activation in lamina propria macrophages of patients with ulcerative colitis Scand J Gastroenterol. 2002;37(4):458-466.

68. Millard AL, Mertes PM, Ittelet D, Villard F, Jeannesson P, Bernard J. Butyrate affects differentiation, maturation and function of human monocyte-derived dendritic cells and macrophages. Clin Exp Immunol. 2002;130(2):245-255.

69. Kaczmarczyk MM, Miller MJ, Freund GG. The health benefits of dietary fiber: beyond the usual suspects of type 2 diabetes mellitus, cardiovascular disease and colon cancer. Metabolism. 2012;61(8):1058-1066.

70. Liu T, Li J, Liu Y, Xiao N, Suo H, Xie K. Short-chain fatty acids suppress lipopolysaccharide-induced production of nitric oxide and proinflammatory cytokines through inhibition of NF- $\mathrm{KB}$ pathway in RAW264.7 cells. Inflammation. 2012;35(5):1676-1684.

71. Voltolini C, Battersby S, Etherington SL, Petraglia F, Norman JE, Jabbour HN. A novel antiinflammatory role for the short-chain fatty acids in human labor. Endocrinology. 2012;153(1):395-403.

72. Vinolo MAR, Ferguson GJ, Kulkarni S, et al. SCFAs induce mouse neutrophil chemotaxis through the GPR43 receptor. PLoS One. 2011; 6(6):2235-2239

73. Tazoe H, Otomo Y, Karaki S, et al. Expression of short-chain fatty acid receptor GPR41 in the human colon. Biomed Res. 2009;30(3):149-156.

74. Park J, Kim M, Kang SG, et al. Short-chain fatty acids induce both effector and regulatory $\mathrm{T}$ cells by suppression of histone deacetylases and regulation of the mTOR S6K pathway. Mucosal Immunol. 2015 8(1):80-93.

75. Arpaia N, Campbell C, Fan X, et al. Metabolites produced by commensal bacteria promote peripheral regulatory T-cell generation. Nature. 2013; 504(7480):451-455.

76. Smith PM, Howitt MR, Panikov N, et al. The microbial metabolites, short-chain fatty acids, regulate colonic Treg cell homeostasis. Science. 2013;341(6145):569-573.

77. Fukuda S. Commensal microbe-derived butyrate induces the differentiation of colonic regulatory T cells. Nature. 2013;504(7480):446-450.

78. Le Poul E, Loison C, Struyf S, et al. Functional characterization of human receptors for short chain fatty acids and their role in polymorphonuclear cell activation. J Biol Chem. 2003;278(28):25481-25489.

79. Vinolo MA, Rodrigues HG, Hatanaka E, Hebeda CB, Farsky SH, Curi R. Short-chain fatty acids stimulate the migration of neutrophils to inflammatory sites. Clin Sci. 2009;117(9):331-338.

80. Vaziri ND, Liu SM, Lau WL, et al. High amylose resistant starch diet ameliorates oxidative stress, inflammation, and progression of chronic kidney disease. PLoS One. 2014;9(12):e114881.

81. Galvez J, Rodriguez-Cabezas ME, Zarzuelo A. Effects of dietary fiber on inflammatory bowel disease. Mol Nutr Food Res. 2005;49(6): 601-608.

82. Burger-Van PN, Vincent A, Puiman PJ, et al. The regulation of intestinal mucin MUC2 expression by short-chain fatty acids: implications for epithelial protection. Biochem J. 2009;420(2):211-219.

83. Hinnebusch BF, Meng S, Wu JT, Archer SY, Hodin RA. The effects of short-chain fatty acids on human colon cancer cell phenotype are associated with histone hyperacetylation. $J$ Nutr. 2002;132(5): 1012-1017.
84. Haberland M, Montgomery RL, Olson EN. The many roles of histone deacetylases in development and physiology: implications for disease and therapy. Nat Rev Genet. 2009;10(1):32-42.

85. Zeng H, Chi H. Metabolic control of regulatory T cell development and function. Trends Immunol. 2015;36(1):3-12.

86. Delgoffe GM, Kole TP, Zheng Y, et al. The mTOR kinase differentially regulates effector and regulatory $\mathrm{T}$ cell lineage commitment. Immunity. 2009;30(6):832-844.

87. Singh N, Thangaraju M, Prasad PD, et al. Blockade of dendritic cell development by bacterial fermentation products butyrate and propionate through a transporter (Slc5a8)-dependent inhibition of histone deacetylases. J Biol Chem. 2010;285(285):27601-27608.

88. Bradford BE, Zhang M, Owyang SY, et al. Butyrate increases IL-23 production by stimulated dendritic cells. Am J Physiol. 2012 303(12):G1384.

89. Frikeche J, Simon T, Brissot E, Gregoire M, Gaugler B, Mohty M. Impact of valproic acid on dendritic cells function. Immunobiology. 2012;217(7):704-710.

90. Hovhannisyan G, Aroutiounian R, Glei M. Butyrate reduces the frequency of micronuclei in human colon carcinoma cells in vitro. Toxicol In Vitro. 2009;23(6):1028-1033.

91. Vecchia MG, Carnelos Filho M, Fellipe CR, Curi R, Newsholme EA. Acetate and propionate potentiate the antiproliferative effect of butyrate on RBL-2H3 growth. Gen Pharmacol. 1997;29(5):725-728.

92. Sakata T, von Engelhardt W. Stimulatory effect of short chain fatty acids on the epithelial cell proliferation in rat large intestine. Comp Biochem Physiol. A Comp Physiol. 1983;74(2):459-462.

93. Pluznick J. A novel SCFA receptor, the microbiota, and blood pressure regulation. Gut Microbes. 2014;5(2):202-207.

94. Pluznick JL. Gut microbiota in renal physiology: focus on short-chain fatty acids and their receptors. Kidney Int. 2016;90(6):1191-1198.

95. Pluznick JL. Microbial short-chain fatty acids and blood pressure regulation. Curr Hypertens Rep. 2017;19(4):25.

96. Nehra V, Allen JM, Mailing LJ, Kashyap PC, Woods JA. Gut microbiota: modulation of host physiology in obesity. Physiology. 2016; 31(5):327-335.

97. Felizardo RJ, Castoldi A, Andrade-Oliveira V, Camara NO. The microbiota and chronic kidney diseases: a double-edged sword. Clin Transl Immunology. 2016;5(6):e86.

98. Ramezani A, Raj DS. The gut microbiome, kidney disease, and targeted interventions. J Am Soc Nephrol. 2014;25(4):657-670.

99. Vaziri ND, Wong J, Pahl M, et al. Chronic kidney disease alters intestinal microbial flora. Kidney Int. 2013;83(2):308-315.

100. Wong J, Piceno YM, Desantis TZ, Pahl M, Andersen GL, Vaziri ND. Expansion of urease- and uricase-containing, indole- and p-cresolforming and contraction of short-chain fatty acid-producing intestinal microbiota in ESRD. Am J Nephrol. 2014;39(3):230-237.

101. Anders HJ, Andersen K, Stecher B. The intestinal microbiota, a leaky gut, and abnormal immunity in kidney disease. Kidney Int. 2013;83(6) 1010-1016.

102. Poesen R, Claes K, Evenepoel P, et al. Microbiota-derived phenylacetylglutamine associates with overall mortality and cardiovascular disease in patients with CKD. $J$ Am SocNephrol. 2016;27(11): 3479-3487.

103. Poesen R, Windey K, Neven E, et al. The influence of CKD on colonic microbial metabolism. J Am Soc Nephrol. 2016;27(5):1389-1399.

104. Bammens B, Evenepoel P, Keuleers H, Verbeke K, Vanrenterghem Y. Free serum concentrations of the protein-bound retention solute $\mathrm{p}$-cresol predict mortality in hemodialysis patients. Kidney Int. 2006;69(6): 1081-1087.

105. Meijers BK, Bammens B, De Moor B, Verbeke K, Vanrenterghem Y, Evenepoel P. Free p-cresol is associated with cardiovascular disease in hemodialysis patients. Kidney Int. 2008;73(10):1174-1180.

106. Sirich TL, Plummer NS, Gardner CD, Hostetter TH, Meyer TW. Effect of increasing dietary fiber on plasma levels of colon-derived solutes in hemodialysis patients. Clin J Am Soc Nephrol. 2014;9(9): 1603-1610. 
107. Ueda H, Shibahara N, Takagi S, Inoue T, Katsuoka Y. AST-120 treatment in pre-dialysis period affects the prognosis in patients on hemodialysis. Ren Fail. 2008;30(9):856-860.

108. Schulman G, Agarwal R, Acharya M, Berl T, Blumenthal S, Kopyt N. A multicenter, randomized, double-blind, placebo-controlled, doseranging study of AST-120 (Kremezin) in patients with moderate to severe CKD. Am J Kidney Dis. 2006;47(4):565-577.

109. Pahl MV, Vaziri ND. The chronic kidney sisease - colonic axis. Semin Dial. 2015;28(5):459-463.

110. Wang H, Zhang W, Zuo L, et al. Bifidobacteria may be beneficial to intestinal microbiota and reduction of bacterial translocation in mice following ischaemia and reperfusion injury. Br J Nutr. 2013; 109(11):1990.

111. Machado RA, Constantino Lde S, Tomasi CD, et al. Sodium butyrate decreases the activation of NF-kappaB reducing inflammation and oxidative damage in the kidney of rats subjected to contrast-induced nephropathy. Nephrol Dial Transplant. 2012;27(8):3136-3140.

112. Sun X, Zhang B, Hong X, Zhang X, Kong X. Histone deacetylase inhibitor, sodium butyrate, attenuates gentamicin-induced nephrotoxicity by increasing prohibitin protein expression in rats. Eur $J$ Pharmacol. 2013;707(1-3):147-154.

113. Abdul Hamid Z, Budin SB, Wen Jie N, Hamid A, Husain K, Mohamed J. Nephroprotective effects of Zingiber zerumbet Smith ethyl acetate extract against paracetamol-induced nephrotoxicity and oxidative stress in rats. J Zhejiang Univ Sci B. 2012;13(3):176-185.

114. Niwa T. Role of indoxyl sulfate in the progression of chronic kidney disease and cardiovascular disease: experimental and clinical effects of oral sorbent AST-120. Ther Apher Dial. 2011;15(2):120-124.

115. Khan S, Jena G. Sodium butyrate, a HDAC inhibitor ameliorates eNOS, iNOS and TGF-beta1-induced fibrogenesis, apoptosis and DNA damage in the kidney of juvenile diabetic rats. Food Chem Toxicol. 2014;73:127-139.

116. Marques FZ, Nelson EM, Chu PY, et al. High fibre diet and acetate supplementation change the gut microbiota and prevent the development of hypertension and heart failure in DOCA-salt hypertensive mice. Circulation. 2017;135(10):964-977.
117. Park J, Goergen CJ, HogenEsch H, Kim CH. Chronically elevated levels of short-chain fatty acids induce T cell-mediated ureteritis and hydronephrosis. J Immunol. 2016;196(5):2388-2400.

118. Zumbrun SD, Melton-Celsa AR, Smith MA, Gilbreath JJ, Merrell DS, O'Brien AD. Dietary choice affects Shiga toxin-producing Escherichia coli (STEC) O157:H7 colonization and disease. Proc Natl Acad Sci US A. 2013;110(23):E2126-E2133.

119. Zumbrun SD, Melton-Celsa AR, O'Brien AD. When a healthy diet turns deadly. Gut Microbes. 2014;5(1):40-43.

120. Shakeel M. Recent advances in understanding the role of oxidative stress in diabetic neuropathy. Diabetes Metab Syndr. 2015;9(4): 373-378.

121. Huang W, Guo HL, Deng X, et al. Short-chain fatty acids inhibit oxidative stress and inflammation in mesangial cells induced by high glucose and lipopolysaccharide. Exp Clin Endocrinol Diabetes. 2017; 125(2):98-105.

122. Matsumoto N, Riley S, Fraser D, et al. Butyrate modulates TGFbetal generation and function: potential renal benefit for Acacia(sen) SUPERGUM (gum arabic)? Kidney Int. 2006;69(2):257-265.

123. Islam M, Burke JF, Mcgowan TA, et al. Effect of anti-transforming growth factor- $\beta$ bgr antibodies in cyclosporine-induced renal dysfunction. Kidney Int. 2001;59(2):498.

124. Isaka $\mathrm{Y}$, Tsujie $\mathrm{M}$, Ando $\mathrm{Y}$, et al. Transforming growth factor- $\beta 1$ antisense oligodeoxynucleotides block interstitial fibrosis in unilateral ureteral obstruction. Kidney Int. 2000;58(5):1885-1892.

125. Peters H, Border WA, Noble NA. Targeting TGF- $\beta$ bgr overexpression in renal disease: maximizing the antifibrotic action of angiotensin II blockade. Kidney Int. 1998;54(5):1570-1580.

126. Rivera MN, Haber DA. Wilms' tumour: connecting tumorigenesis and organ development in the kidney. Nat Rev Cancer. 2005;5(9): 699-712.

127. Tan W, Chen Y, An P, et al. Sodium butyrate-induced histone hyperacetylation up-regulating WT1 expression in porcine kidney fibroblasts. Biotechnol Lett. 2015;37(6):1195-1202.
Drug Design, Development and Therapy

\section{Publish your work in this journal}

Drug Design, Development and Therapy is an international, peerreviewed open-access journal that spans the spectrum of drug design and development through to clinical applications. Clinical outcomes, patient safety, and programs for the development and effective, safe, and sustained use of medicines are the features of the journal, which

\section{Dovepress}

has also been accepted for indexing on PubMed Central. The manuscript management system is completely online and includes a very quick and fair peer-review system, which is all easy to use. Visit http://www.dovepress.com/testimonials.php to read real quotes from published authors. 